\title{
Sebuah Penelitian Empiris tentang Hubungan Masa Kerja, Kualitas Sumber Daya Manusia dan Komitmen Organisasi
}

\author{
Rahayu Mardikaningsih \\ Fakultas Ekonomi Universitas Mayjen Sungkono Mojokerto \\ email: rahayumardikaningsih@gmail.com
}

\section{Kata kunci:}

Masa Kerja

Kualitas Sumber Daya Manusia

Komitmen Organisasi

\section{Keywords:}

Tenure

Human Resource Quality

Organizational Commitment

Rahayu Mardikaningsih. (2020). Sebuah Penelitian Empiris tentang Hubungan Masa Kerja, Kualitas Sumber Daya Manusia dan Komitmen Organisasi. Akuntabilitas: Jurnal Ilmiah IlmuIlmu Ekonomi, 13(1), 43-54

\begin{abstract}
ABSTRAK
Hubungan antara pegawai dan organisasi telah lama menjadi topik penelitian lebih lanjut. Masa kerja merupakan wujud dari hubungan antara keduanya. Hasil dari hubungan tersebut dapat berupa komitmen organisasi dan kualitas sumber daya manusia. Proposisi tersebut memiliki asumsi bila praktek dan pengembangan sumber daya manusia berorientasi pada keseimbangan dua belah pihak. Untuk membuktikan proposisi tersebut dilakukan penelitian empiris yang melibatkan tiga variabel yang relevan, yaitu masa kerja, kualitas sumber daya manusia dan komitmen organisasi. Penelitian ini bertujuan untuk (1) untuk mengetahui hubungan antara masa kerja dan kualitas sumber daya manusia; (2) untuk mengetahui hubungan antara masa kerja dan komitmen organisasi; dan (3) untuk mengetahui hubungan antara kualitas sumber daya manusia dan komitmen organisasi. Alat analisisnya menggunakan analisis korelasi melalui program SPSS. Total populasi sebanyak 567 pegawai dengan jabatan pelaksana. Penelitian dilakukan di salah satu BUMN di Jawa Barat. Peneliti menetapkan jumlah sampel sebanyak 60 orang dengan teknik acak. Simpulan dari hasil penelitian ini, yaitu (1) masa kerja pegawai memiliki hubungan yang cukup kuat dengan kualitas sumber daya manusia; (2) masa kerja pegawai memiliki hubungan yang cukup kuat dengan komitmen organisasi; dan (3) kualitas sumber daya manusia memiliki hubungan yang cukup kuat dengan komitmen organisasi.
\end{abstract}

\section{ABSTRACT}

The relationship between employees and organizations has long been a topic of further research. Working period is a form of the relationship between the two. The results of these relationships can be in the form of organizational commitment and human resource quality. The proposition assumes that the practice and development of human resources is oriented towards the balance of the two parties. To prove the proposition an empirical study was conducted involving three relevant variables, namely tenure, human resource quality and organizational commitment. This study aims to (1) find out the relationship between tenure and human resource quality; (2) to find out the relationship between tenure and organizational commitment; and (3) to determine the relationship between human resource quality and organizational commitment. The analysis tool uses correlation analysis through the SPSS program. The total population of 567 employees with executive positions. The study was conducted at BUMN in West Java. Researchers set a sample size of 60 people with random techniques. Conclusions from the results of this study, namely (1) employee tenure has a fairly strong relationship with human resource quality; (2) employee tenure has a strong enough relationship with organizational commitment; and (3) human resource quality has a strong enough relationship with organizational commitment. 


\section{PENDAHULUAN}

Setiap perusahaan tentu menginginkan pegawainya untuk tetap bekerja berdasarkan masa kerja yang ditentukan karena untuk membantu mempertahankan perusahaannya. Pegawai yang ditempatkan pada posisi yang tepat maka dapat bekerja dengan baik sehingga kinerja perusahaan secara menyeluruh lebih optimal. Setiap pegawai tentu memiliki kemampuan, kecerdasan, keterampilan, potensi yang dapat berubah dan berkembang. Kemampuan pegawai dapat meningkat melalui pelatihan, kecerdasan dapat meningkat melalui belajar dan keterampilan dapat ditingkatkan dengan mengerjakan pekerjaan secara berulang. Pegawai dengan masa kerja lebih lama tentu memilki keterampilan dan pengalaman yang lebih banyak (Robbins dan Judge, 2008). Masa kerja sebagai penentu lamanya pegawai yang dipekerjakan oleh pemberi kerja. Selain itu, masa kerja dihubungkan dengan seberapa lama pekerja melakukan pekerjaan sampai memperoleh kepuasan yang diinginkan. Masa kerja pegawai dapat menjadi investasi yang berhubungan dengan rekan kerja, masa pensiun, karir, keterampilan yang akan mendukung kompetensinya. Pegawai yang telah bekerja selama beberapa tahun memiliki kualitas dan pengalaman yang bermanfaat sebagai aset berharga untuk perusahaan (Nwankwo et al., 2013). Hal ini menunjukkan bahwa masa kerja dan kualitas sumber daya manusia saling berhubungan. Hal ini berdasarkan temuan dari penelitian sebelumnya yang menyatakan bahwa masa kerja pegawai memiliki hubungan yang kuat dengan kualitas sumber daya manusia (Shah et al., 2003; Nwankwo et al., 2013).

Masa kerja yang lebih lama dapat mendukung pegawai untuk memiliki kinerja yang baik dan dapat diandalkan. Menurut Van Vugt (2006) ada hubungan antara pengetahuan, masa kerja, kinerja dengan pengalaman dan pengetahuan khusus. Hassan dan Ogunkoya (2014) juga menyatakan bahwa masa kerja dengan kinerja saling berhubungan positif. Masa kerja pegawai memberikan kontribusi terhadap kinerja (Schmidt et al., 1986) dan berhubungan positif dengan kinerja (McDaniel et al., 1988). Pegawai dengan masa kerja yang singkat menilai pemberdayaan sebagai kebutuhan dasar akan rasa percaya diri ketika mereka menyesuaikan diri dengan lingkungan perusahaan (Huang et al., 2006). Pernyataan tersebut juga didukung oleh Dickson dan Lorenz (2009) bahwa masa kerja berhubungan positif dengan pemberdayaan pegawai 
secara psikologis. Sebaliknya, pegawai dengan masa kerja yang lebih lama cenderung tidak membutuhkan pemberdayaan karena mereka merasa telah memiliki pengalaman yang memberikan tantangan dan motivasi (Foster-Fishman et al., 1994). Pernyataan tersebut tidak sesuai dengan pendapat Ozaralli (2003) karena pegawai dengan masa kerja yang lebih lama akan lebih diberdayakan karena pemberdayaan berhubungan dengan masa kerja untuk menilai pengalaman. Ada dua penjelasan tentang masa kerja pegawai, yaitu (1) masa kerja sebagai komitmen dari pegawai yang telah memberikan bukti bagaimana kemampuan kerjanya sehingga mampu menjaga hubungan yang lebih lama dengan pimpinannya (Krueger dan Kilham, 2005); (2) masa kerja pegawai sebagai periode waktu pegawai terlibat dalam suatu perusahaan secara aktif dan terus-menerus (Marisa dan Sonia, 2005). Dengan demikian masa kerja adalah komitmen dan keterlibatan pegawai terhadap pekerjannya selama priode waktu tertentu sehingga memiliki kemampuan yang dapat dibuktikan. Menurut Hasan dan de Broucker (1985) indikator yang mendasari masa kerja ada tiga, diantaranya (1) kendala yang terjadi selama menyelesaikan pekerjaan (kendala jumlah waktu); (2) kesesuaian selama menyelesaikan pekerjaan. Menurut Akerlof dan Main (1981) termasuk pengalaman yang menguntungkan; dan (3) kesesuaian terhadap pekerjaan baru (digunakan untuk mendukung pekerjaan dalam jangka waktu yang lebih lama).

Masa kerja juga memiliki korelasi positif terhadap komitmen organisasi seperti yang dinyatakan oleh Cohen (1993). Perusahaan yang berusaha untuk membina hubungan dengan sumber daya manusianya selalu memperhatikan dan mengembangkan cara-cara baru untuk memenuhi kebutuhan dan harapan pegawai. Upaya tersebut dapat memberikan kepuasan dan menumbuhkan komitmen organisasi bagi pegawai. Curry et al. (1986) menjelaskan bahwa komitmen organisasi adalah kekuatan individu yang dapat diidentifikasi dan bersedia terlibat terhadap organisasi tertentu. Komitmen organisasi dibentuk oleh tiga elemen yang solid. Tiga elemen tersebut menurut Allen dan Meyer (1990) adalah komitmen afektif, komitmen berkesinambungan, dan komitmen normatif. Ketiga elemen tersebut menunjukkan adanya rasa ingin mengabdi kepada organisasi dengan wujud menunjukkan perilaku kerja yang baik dan berkontribusi maksimal serta bertekad untuk tetap bersama organisasi. 
Kualitas sumber daya manusia juga memiliki hubungan dengan komitmen organisasi. Peran sumber daya manusia (SDM) tidak diragukan lagi, karena memberikan kontribusi kepada suatu perusahaan. Istilah SDM menunjukkan adanya potensi, kemampuan, kualitas, keterampilan. Produktivitas dan pertumbuhan perusahaan, perkembangan ekonomi sebagian besar behubungan dengan pemanfaatan kualitas SDM yang efektif. Kualitas SDM sebagai SDM yang mampu bersikap profesional ketika bekerja dan memiliki keterampilan (Hrab, 2014). Oleh karena itu, sangat penting bagi perusahaan untuk mengambil langkah bagaimana memanfaatkan kualitas sumber daya manusia dengan efektif. Salah satu langkah yang dapat dilakukan yaitu dengan perencanaan sumber daya manusia yang efektif. Perencanaan sumber daya manusia sebagai salah satu cara untuk menetapkan apa yang dibutuhkan tenaga kerja termasuk kualitas dan kuantitas pada suatu periode dan dilakukan dengan cara yang telah ditentukan (Barry, 2002). Perencanaan yang dilakukan memiliki tujuan agar perusahaan tidak mengalami kelangkaan sumber daya manusia yang berkualitas sesuai kebutuhan perusahaan. Kelangkaan sumber daya manusia tidak akan terjadi bila masing-masing pegawai memiliki komitmen organisasi yang kuat. Tidak adanya keinginan untuk meninggalkan organisasi menyebabkan perencanaan terhadap sumber daya manusia yang dilakukan organisasi tidak akan terkendala dan tetap berjalan sebagaimana yang direncanakan. Sumber daya manusia yang berkualitas tentu memiliki kompetensi dan kompetensi yang dimiliki dapat dikembangkan melalui pengembangan sumber daya manusia (Rao, 1995). Menurut Eiglier dan Langeard (1987) indikator yang mendasari kualitas sumber daya manusia ada tiga, diantaranya (1) kompetensi; (2) penampilan pegawai; dan (3) perilaku dan sikap.

Berdasarkan uraian sebelumnya, penulis menetapkan judul : Sebuah Penelitian Empiris tentang Hubungan Masa Kerja, Kualitas Sumber Daya Manusia dan Komitmen Organisasi. Penelitian dilakukan di salah satu BUMN di Kecamatan Cikampek, Kabupaten Karawang, Jawa Barat. Penelitian ini bertujuan untuk (1) untuk mengetahui hubungan antara masa kerja dan kualitas sumber daya manusia; (2) untuk mengetahui hubungan antara masa kerja dan komitmen organisasi; dan (3) untuk mengetahui hubungan antara kualitas sumber daya manusia dan komitmen organisasi. 


\section{METODE PENELITIAN}

Jenis penelitian ini yaitu survei dan ex post facto. Alat analisisnya menggunakan analisis korelasi melalui program SPSS. Sampel direncanakan diambil sebagian dari 567 pegawai dengan jabatan pelaksana di salah satu BUMN yang berlokasi di Kecamatan Cikampek, Kabupaten Karawang, Jawa Barat. Peneliti menetapkan sebanyak kurang lebih 10 persen dari 567 pegawai. Dengan demikian jumlah sampel sebanyak 60 orang.

Variabel yang dikaji pada penelitian ini, yaitu masa kerja (X.1), kualitas sumber daya manusia (X.2), dan komitmen organisasi (X3). Berikut ini akan diuraikan penjelasan dari variabel tersebut. Masa kerja (X.1) adalah komitmen dan keterlibatan pegawai terhadap pekerjaannya selama periode waktu tertentu sehingga memiliki kemampuan yang dapat dibuktikan (Krueger dan Kilham, 2005; Marisa dan Sonia, 2005). Indikator yang mendasari masa kerja ada tiga, diantaranya (1) kendala yang terjadi selama menyelesaikan pekerjaan (kendala jumlah waktu); (2) kesesuaian selama menyelesaikan pekerjaan, menurut Akerlof dan Main (1981) termasuk pengalaman yang menguntungkan; dan (3) kesesuaian terhadap pekerjaan baru (digunakan untuk mendukung pekerjaan dalam jangka waktu yang lebih lama) (Hasan dan de Broucker ,1985).

Kualitas sumber daya manusia (X.2) adalah sumber daya manusia yang mampu bersikap profesional ketika bekerja dan memiliki keterampilan (Hrab, 2014). Indikator yang mendasari kualitas sumber daya manusia ada tiga, yaitu (1) kompetensi; (2) penampilan pegawai; dan (3) perilaku dan sikap (Eiglier dan Langeard, 1987).

Menurut Allen dan Meyer (1990), komitmen organisasi (X3) adalah keadaan psikologis yang berhubungan dengan pegawai dan organisasi sehingga pegawai memutuskan untuk tetap bersama organisasinya. Hal tersebut ditunjukkan dengan indikatornya sebagai berikut: (1) komitmen afektif (affective commitment); (2) komitmen berkesinambungan (continuance commitment); (3) komitmen normatif (normative commitment).

Sumber data pada penelitian ini terdiri dari data primer dan data sekunder. Data primer diperoleh dari pembagian kuesioner secara langsung kepada 60 pegawai. Jawaban dari kuesioner menggunakan skala likert, Ada delapan alternatif 
jawaban yang ditetapkan, yaitu sangat setuju sekali (8); sangat setuju (7); setuju (6); agak setuju (5); kurang setuju (4); tidak setuju (3); sangat tidak setuju (2); sangat tidak setuju sekali (1). Data sekunder merupakan sumber data penelitian yang diperoleh peneliti secara tidak langsung melalui media perantara (diperoleh dari pihak lain).

\section{HASIL DAN PEMBAHASAN}

Responden yang terkumpul sebanyak 60 orang yang akan dianalisis lebih lanjut. Pertama adalah uji validitas yang ditunjukkan pada Tabel 1. Batas minimal untuk setiap butir instrumen dinyatakan valid adalah nilai corrected item-total correlation tidak kurang dari 0,3 .

Tabel 1

Uji Validitas

\begin{tabular}{|c|c|c|c|c|}
\hline No & Variabel & Topik Pertanyaan & $\begin{array}{c}\text { Corrected item- } \\
\text { total } \\
\text { Correlation }\end{array}$ & Status \\
\hline \multirow[t]{6}{*}{1} & \multirow{6}{*}{$\begin{array}{l}\text { Masa } \\
\text { Kerja }\end{array}$} & Beragam kendala yang pernah dialami selama bekerja & 0,773 & Valid \\
\hline & & Waktu diperlukan untuk merasa menjadi bagian organisasi & 0,748 & Valid \\
\hline & & Kesesuaian selama menyelesaikan pekerjaan & 0,859 & Valid \\
\hline & & Pengalaman yang menguntungkan & 0,759 & Valid \\
\hline & & Kesesuaian terhadap pekerjaan baru & 0,843 & Valid \\
\hline & & Jenjang karir yang telah dirasakan & 0,835 & Valid \\
\hline \multirow[t]{6}{*}{2} & \multirow{6}{*}{$\begin{array}{c}\text { Kualitas } \\
\text { Sumber Daya } \\
\text { Manusia }\end{array}$} & Konsisten kualitas kerja yang dihasilkan pegawai & 0,727 & Valid \\
\hline & & Potensi untuk terus berkembang & 0,856 & Valid \\
\hline & & Bukti dari hasil kerja & 0,885 & Valid \\
\hline & & Ketaatan terhadap aturan & 0,837 & Valid \\
\hline & & Perilaku kerja yang mendukung pekerjaan & 0,746 & Valid \\
\hline & & Sikap yang dapat diterima oleh lingkungan kerja & 0,854 & Valid \\
\hline \multirow[t]{6}{*}{3} & \multirow{6}{*}{$\begin{array}{l}\text { Komitmen } \\
\text { Organisasi }\end{array}$} & Sikap untuk menekuni pekerjaannya & 0,736 & Valid \\
\hline & & Keinginan untuk terlibat dengan organisasinya & 0,786 & Valid \\
\hline & & Sikap merasa beruntung bersama organisasi & 0,884 & Valid \\
\hline & & Ada kerugian bila meninggalkan organisasi & 0,774 & Valid \\
\hline & & Sikap loyalitas terhadap organisasi & 0,883 & Valid \\
\hline & & Kewajiban untuk tetap bersama organisasinya & 0,814 & Valid \\
\hline
\end{tabular}

Sumber : data dioleh oleh peneliti dari output SPSS , 2020

Berdasarkan Tabel 1 disimpulkan bahwa semua item pernyataan dari masingmasing variabel nilainya melebihi 0,3. Dengan demikian setiap item pernyataan tersebut dinyatakan valid. Selanjutnya adalah uji reliabilitas seperti pada Tabel 2.

Tabel 2

Uji Reliabilitas

\begin{tabular}{clcc}
\hline No & \multicolumn{1}{c}{ Variabel } & Cronbach's alpha & Status \\
\hline 1 & Masa Kerja & 0,948 & Reliabel \\
\hline 2 & Kualitas Sumber Daya Manusia & 0,906 & Reliabel \\
\hline 3 & Komitmen Organisasi & 0,952 & Reliabel \\
\hline
\end{tabular}

Sumber : output SPSS , 2020 
Suatu instrumen dinyatakan reliabel bila nilai cronbach alpha menunjukkan lebih dari 0,7. Instrumen dinyatakan tidak reliabel bila nilai cronbach alpha kuran dari 0,7. Berdasarkan output SPSS menunjukkan cronbach's alpha menunjukkan nilai lebih dari 0,7 . Dengan demikian setiap variabel dinyatakan telah reliabel.

Setelah diproses sebelumnya semua indikator dan variabel dinyatakan valid dan reliabel maka langkah selanjutnya adalah menghubungkan variabel penelitian dengan menggunakan alat analisis korelasi Rank Spearman. Hasilnya ditunjukkan pada Tabel 3 .

Tabel 3

Correlations

\begin{tabular}{|c|c|c|c|c|c|}
\hline & & & $\mathrm{X} 1$ & $\mathrm{X} 2$ & $\mathrm{X} 3$ \\
\hline \multirow[t]{9}{*}{ Spearman's rho } & \multirow[t]{3}{*}{$\mathrm{X} 1$} & Correlation Coefficient & 1.000 & $.649^{* *}$ & $.503^{* *}$ \\
\hline & & Sig. (2-tailed) & . & .000 & .000 \\
\hline & & $\mathrm{N}$ & 60 & 60 & 60 \\
\hline & \multirow[t]{3}{*}{$\mathrm{X} 2$} & Correlation Coefficient & $.649^{* *}$ & 1.000 & $.689^{* *}$ \\
\hline & & Sig. (2-tailed) & .000 & . & .000 \\
\hline & & $\mathrm{N}$ & 60 & 60 & 60 \\
\hline & \multirow[t]{3}{*}{ X3 } & Correlation Coefficient & $.503^{* \star}$ & $.689^{* *}$ & 1.000 \\
\hline & & Sig. (2-tailed) & .000 & .000 & \\
\hline & & $\mathrm{N}$ & 60 & 60 & 60 \\
\hline
\end{tabular}

**. Correlation is significant at the 0.01 level (2-tailed).

Sumber : output SPSS , 2020

Hasil output SPSS pada Tabel 3 menunjukkan masing-masing nilai korelasi setiap hubungan variabel. Angka koefisien korelasi spearman variabel masa kerja dengan variabel kualitas sumber daya manusia sebesar 0,649 yang cukup kuat di antara keduanya dan hubungan bersifat positif. Semakin panjang masa kerja maka semakin meningkat pada titik tertentu kualitas sumber daya manusia.

Angka koefisien korelasi spearman variabel masa kerja dengan variabel komitmen organisasi sebesar 0,503 yang cukup kuat di antara keduanya dan hubungan bersifat positif. Semakin panjang masa kerja maka semakin kuat komitmen organisasi pada titik tertentu.

Angka koefisien korelasi spearman variabel kualitas sumber daya manusia dengan variabel komitmen organisasi sebesar 0,689 yang cukup kuat di antara keduanya dan hubungan bersifat positif. Semakin baik kualitas sumber daya manusia maka semakin kuat komitmen organisasi pada titik tertentu. 
Berdasarkan hasil yang diperoleh dari jawaban responden melalui kuesioner yang telah disebarkan serta hasil analisis korelasi sebelumnya dapat dinyatakan bahwa masa kerja pegawai dan kualitas sumber daya manusia saling berhubungan. Hasil penelitian berdasarkan pembuktian hipotesis menunjukkan bahwa masa kerja pegawai memiliki hubungan yang cukup kuat dengan kualitas sumber daya manusia (Shah et al., 2003; Nwankwo et al., 2013). Pihak Manajamen dapat memberikan kepuasan kerja kepada pegawainya karena masa kerja dapat meningkat melalui kepuasan (Olatunji dan Mukuolu, 2014). Pegawai dengan masa kerja 5-10 tahun cenderung lebih puas dibandingkan pegawai yang masa kerjanya kurang dari 5 tahun. Masa kerja pegawai akan memberikan pengalaman yang mendukung kompetensi pegawai. Pengalaman dapat mengurangi tingkat stres dan meningkatkan kepuasan (Olatunji dan Mukuolu, 2014). Oshagbemi (2000) menyatakan bahwa masa kerja berhubungan positif dan signifikan terhadap kepuasan kerja. Pegawai dengan masa kerja yang lebih lama menunjukkan bahwa kepuasan yang dirasakan juga tinggi karena telah menemukan pekerjaan yang sesuai dengan kebutuhannya sehingga dapat mempromosikan kualitas dirinya. Selanjutnya, perusahaan perlu memantau sejauh mana para pegawainya telah mecapai kepuasan kerja. Hasil pemantuan tersebut sebagai evaluasi perusahaan terhadap sejauh mana perusahaan telah memenuhi harapan pegawai. Perusahaan yang teliti dan bijak terhadap analisis dan evaluasi tingkat kepuasan kerja pegawainya maka selanjutnya akan mempengaruhi kegiatan manajemen sumber daya manusia secara keseluruhan. Dari penjelasan sebelumya menunjukkan bahwa masa kerja pegawai dan kualitas sumber daya manusia saling berhubungan.

Hipotesis lain menyatakan bahwa masa kerja punya korelasi cukup kuat bersama komitmen organisasi. Temuan tersebut mendukung juga temuan dari Cohen (1993). Menurut Bakker et al. (2011), organisasi memerlukan pekerja yang secara psikologis terikat pada pekerjaan mereka, di saat sekarang dan di masa depan. Masa kerja telah menunjukkan keterikatan tersebut yang diwujudkan melalui komitmen organisasi. Pekerja yang memiliki masa kerja panjang memungkinkan untuk merasa didukung dan diperhatikan oleh organisasi sehingga mereka tetap dipertahankan berada di organisasi. Proses timbal balik dari hal tersebut memunculkan komitmen, 
yang merupakan bentuk ikatan psikologis atas kehendak yang mencerminkan dedikasi dan tanggung jawab untuk target tertentu (Klein et al., 2012).

Hipotesis lainnya telah terbukti bahwa kualitas sumber daya manusia memiliki hubungan yang cukup kuat dengan komitmen organisasi. Hal ini menurut Eisenberger et al. (1990) menunjukkan timbal balik penting dalam pengembangan komitmen organisasi. Pegawai memiliki kecenderungan untuk menjadi lebih berkomitmen dalam suatu organisasi jika upaya mereka diakui dan dihargai melalui hasil kerja mereka. Mereka yang fokus memberikan hasil kerja terbaik merupakan sumber daya manusia yang berkualitas. Menurut Darmawan (2019), pegawai yang tidak puas dengan pekerjaan mereka menyebabkan mereka mendapatkan tekanan psikologis dan ketidakadilan yang dirasakan di tempat kerja. Hal ini memunculkan kemungkinan melemahnya komitmen organisasi. Berdasarkan teori pertukaran sosial menyatakan bahwa persepsi pegawai terhadap praktik manajemen sumber daya manusia menentukan rasa timbal baliknya serta tingkat tingkat komitmen organisasi pegawai terhadap organisasi (Oligivie, 1986). Salah satu tujuan utama dari praktik manajemen sumber daya manusia adalah pengembangan potensi dan kualitas sumber daya manusia. Dengan demikian menurut Oligivie (1986) faktor-faktor yang meningkatkan komitmen organisasi di antara pegawai telah diidentifikasi sebagai praktik dan kebijakan manajemen sumber daya manusia. Hasilnya adalah bahwa pegawai percaya bahwa organisasi akan memberikan imbalan simbolis dan nyata sebagai imbalan atas upaya dan komitmen mereka. Oleh karena itu, praktik manajemen sumber daya untuk meningkatkan kualitasnya adalah cara praktis untuk menumbuhkan komitmen pegawai, dan telah ditemukan bahwa ada hubungan positif antara kualitas sumber daya manusia dan komitmen organisasi.

\section{KESIMPULAN}

Berdasakan hasil dari analisis dan pembahsan sebelumnya maka simpulan dari hasil penelitian ini, yaitu (1) masa kerja pegawai memiliki hubungan yang cukup kuat dengan kualitas sumber daya manusia; (2) masa kerja pegawai punya korelasi cukup kuat bersama komitmen organisasi; dan (3) kualitas sumber daya manusia memiliki korelasi cukup kuat bersama komitmen organisasi. 
Berdasarkan hasil dari analisis, pembahasan dan simpulan sebelumnya maka ada beberapa saran yang dapat diberikan oleh peneliti. Kualitas sumber daya manusia yang memiliki hubungan dengan komitmen organisasi membuktikan bahwa faktorfaktor penentu seperti pelatihan, pendidikan, kompensasi, kontinjensi imbalan-kinerja, pengembangan karir atau promosi perlu lebih diterapkan sejalan dengan tujuan organisasi dan hal itu melibatkan hubungan jangka panjang antara pegawai dan organisasi. Hubungan jangka panjang yang terjalin ditunjukkan dengan masa kerja dan komitmen organisasi. Oleh karena itu perlu juga untuk melakukan pengembangan sumber daya manusia melalui pendidikan dan pelatihan yang dapat (1) membantu pegawai untuk lebih efektif ketika bekerja di masa sekarang atau masa depan; (2) meningkatkan pengetahuan, keterampilan dan sikap pegawai sesuai dengan kebutuhan perusahaan; (3) melakukan rotasi jabatan dengan tujuan untuk memberikan pemahaman operasional kepada pegawai secara bertahap selain variasi pekerjaan yang dilakukan selama masa kerjanya yang penuh kerutinan, memberikan pengetahuan baru yang berhubungan dengan berbagai jabatan, melakukan promosi sebagai upaya mengembangkan pegawai untuk menerima tugas, wewenang, tanggungjawab yang lebih besar dari pekerjaan yang sebelumnya.

\section{DAFTAR PUSTAKA}

Allen, N. J., \& J. P.M. Meyer. 1990. The Measurement and Antecedents of Affective, Continuance \& Normative Commitment to the Organization. Journal of Occupational Psychology, Vol. 63 Issue 1, pp. 1-18.

Akerlof, George A., \& Brian G.M. Main, 1981. An Experinced-Weighted Measure of Employment and Unemployment Duration. American Economic Review, Vol. 7, pp. 1003-1011.

Bakker, A. B., Albrecht, S. L., \& Leiter, M. PP. 2011. Key Questions Regarding Work Engagement. European Journal of Work and Organizational Psychology, Vol. 20, pp. 4-28.

Barry, Cushway. 2002. Manajemen Sumber Daya Manusia Perencanaan-Analisis-KinerjaPenghargaan, Alih Bahasa oleh Paloepi Tyas R. Jakarta. Komputindo.

Brimeyer, Ted M., Robert Perrucci \& Shelley MacDermid Wadsworth. 2010. Age, Tenure, Resources for Control \& Organizational Commitment, Social Science Quarterly, Vol. 91, No. 2, pp. 511-530

Cohen, Aaron. 1993. Age \& Tenure in Relation to Organizational Commitment: A Meta-Analysis, Basic and Applied Social Psychology, Vol. 14 No. 2, pp.143-159 
Darmawan, Didit. 2019. Profesionalisme, Motivasi Berprestasi, Komitmen Organisasi dan Pengaruhnya terhadap Intensi Berwirausaha Ekuitas: Jurnal Ekonomi dan Keuangan, Vol.3, No. 3, pp. 344-364

Dickson, K. E., \& Lorenz, A. 2009. Psychological Empowerment and Job Satisfaction of Temporary and Part-Time Non-Standard workers: A preliminary investigation. Institute of Behavioral and Applied Management, Vol. 24, No. 1, pp. 166-191

Eiglier., \& Langeard. 1987. Servuction, Le Marketing Des Services, Ed. Mc Garw Hill, London.

Eisenberger, R., Fasolo, P., \& Davis-LaMastro, V. 1990. Perceived Organizational Support and Employee Diligence, Commitment, and Innovation. Journal of Applied Psychology, 75(1), pp. 51.

Foster-Fishman, P. G., Salem, D. A., Chibnall, S., Legler, R., \& Yapchai, C. 1998. Empirical Support for the Critical Assumptions of Empowerment Theory. American Journal of Community Psychology, Vol. 26, pp. 507-536.

Hasan, Abrar., \& P.de Broucker. 1985. Unemployment, Employment, and NonParticipation in Canadian Labour Markets, Minister of Supply and Services Canada.

Hassan, B., \& Ogunkoya, O. 2014. Demographic Variables and Job Performance: Any Link? (A Case of Insurance Salesmen). Acta Universitatis Danubius. CEconomica, Vol. 10, No. 4, pp. 19-30.

Hrab, Andreea. 2014. What 6 Qualities Make a Good Human Resources Professional. Employee Relations.

Huang, X., Shi, K., Zhang, Z., \& Cheung, Y. L. 2006. The Impact of Participative Leadership Behaviour on Psychological Empowerment \& Organizational Commitment in Chinese State-owned Enterprises: The moderating role of organizational tenure. Asia Pacific Journal Manage, Vol. 23, No. 1, pp. 345-357.

Klein, H. J., Molloy, J. C., \& Brinsfield, C. T. 2012. Reconceptualizing Workplace Commitment to Redress a Stretched Construct: Revisiting Assumptions \& Removing Confounds. Academy of Management Review, Vol.37, pp. 130-151.

Krueger, J., \& Kiellham, E. 2005. At Work, Feeling Good Matters: Happy employees are better equipped to handle workplace relationships, change \& stress, according to the latest GMJ survey. Gallup Management Journal.

Marisa, S., \& Sonyia, A. 2005. Linking Organizational Resources \& Work Engagement to Employee Performance \& Customer Loyalty: The mediation of service climate. Journal of Applied Psychology, Vol. 90, No. 6, pp. 1217-1227.

McDaniel, M. A., Schmidt, F. L., \& Hunter, J. E. 1988. Job Experience correlates of job Performance. Journal of Applied Psychology, Vol. 73, No. 2, pp. 327-330.

Nwankwo, Dr Barhnabas E., Tobias, C.Obi., Dr Ngozi Sydney-Agbor., Solomon, A.Agu., \& Dr James U Aboh. 2013. Influence Pay Satisfaction \& Lenght of Service on Organization Citizenship Behaviour of Bankers. International Journal of Academic Research in Business and Social Science. Vol. 3, No. 9, pp. 238-244.

Olatunji, S. O. \& Mokuoolu, B. O. 2014. The Influence of Marital Status, Sex \& Tenure of Service on Job Stress, \& Job Satisfaction of Health Workers in a Nigerian Federal Health Institution. African Research Review, Vol. 8, Issue. 1, No. 32, pp. 126-133. 
Ogilvie, J. R. 1986. The Role of Human Resource Management Practices in Predicting Organizational Commitment. Group \& Organization Management, 11(4), 335-359

Oshagbemi, T. 2000. Is Length of Service Related to the Level of Job Satisfaction.? International Journal of Social Economics, Vol. 27, pp. 213-26.

Ozaralli, N. 2003. Effects of Transformational Leadership on Empowerment \& Team Effectiveness. Leadership E Organization Development Journal, Vol 24, No. 5/6, pp. 335- 345.

Rao, T.V. 1995. Human Resources Development, Experiences, Interventions, Strategies National Book Foundation, Islamabad, Pakistan.

Robbins, S. P., \& Judge, T. A. 2008. Organization Behavior. 15th edition, Boston, Pearson.

Schmidt, F. L., Hunter, J. E., \& Outerbridge, A. N. 1986. The Impact of Job Experience and Ability on Job Knowledge, Work Sample Performance, and Supervisory Ratings of Job Performance. Journal of Applied Psychology, Vol. 71, No. 3, pp. 432-439.

Shah, J. S., Crossman, A. \& Parkpoom, C. 2003. The Relationships of Age \& Length of Services with Job Satisfaction, an Examination of Hotel Employees in Thailand. Journal of Managerial Psychology, Vol. 18, No. 7, pp. 745 - 758.

Van Vugt, M. 2006. Evolutionary Origins of Leadership and Followership. Personality E Social Psychology Review. Vol. 10, No. 4, pp. 354-371. 